\title{
Utility of Screening Test in Early Diagnosis of Urinary Tract Infection in Children
}

\author{
Smita Bawankar, Aakanksha Sharma*, Khyati Jain, Surendra Chauhan and Mustafa
}

Department of Microbiology, Shri Shankaracharya Institute of Medical Sciences, Bhilai, India

*Corresponding author:

\section{A B S T R A C T}

\section{Keywords}

Urinary tract infection, Asymptomatic bacteriuria, Semiquantative culture, Screening tests

Article Info

Accepted:

12 December 2018

Available Online:

10 January 2019
Urinary tract infection (UTI) is a common disease affecting especially infants and young children. The clinical presentations are diverse, from an unaffected infant with asymptomatic bacteriuria to a severely septic child. Accurate and timely diagnosis and treatment is important for the prevention of long-term morbidity and sequelae (e.g. hypertension, proteinuria, and chronic kidney disease). The purpose of the present study was to determine the validity of rapidly diagnostic tests for the early detection of UTIs in paediatric patients. Total 247 midstream urine specimens were processed. On one part of sample semiquantitative culture was done and on another part various screening test (wet mount, Gram's stain, catalase test, triphenyl tetrazolium chloride test and modified Griess nitrate test) were performed and compared with culture. Out of 247 urine samples, 58(23.48\%) samples were culture positive. E. coli was most common bacteria pathogen isolated. Among screening tests, modified Griess nitrate test and TTC test were more specific. While catalase test and Gram stain were both sensitive and specific. Wet mount examination found to be the least useful test. Combination of screening test can be helpful especially in setup where laboratory facility for culture is not available for diagnosis of urinary tract infection.

\section{Introduction}

Urinary tract infection (UTI) is recognized increasingly as a common cause of fever in young children. Urinary tract infection (UTI) is a common serious bacterial infection in childhood. However, clinical findings indicative of UTI in this group are often subtle and nonspecific, with fever often the only finding (Gorelick et al., 1999). The importance of UTIs is reflected not only by their frequency but also by the range of clinical severity that may occur, from asymptomatic to mild or moderate symptomatic lower UTI to bacteremia and septic shock. In addition, it has been shown that UTIs with fever in young children increase the probability of kidney involvement and are associated with an increased risk of underlying nephrourologic abnormalities and consequent renal scarring (Christopher et al., 2016). It affects male children more than female in first year of life and female after 1 year of age. There are several risk factors for pediatric urinary tract infections. Neonates and infants in their first few months of life are at 
higher risk for UTI. This susceptibility has been attributed to an incompletely developed immune system. Clinical presentation of UTI in infants and young children can be very subtle and atypical and a high index of suspension must be kept in order to diagnose (Gorelick et al., 1999). UTI in Children should be suspected if there is presence of fever, chills and rigor, burning micturation, foul smelling of urine, pain abdomen, vomiting, facial puffiness, loose stool, seizures, hematuria, constipation, loss of appetite and failure to thrive (Shrestha et al., 2013; Elder et al., 2007).

The management and diagnosis of UTI in children are different from adults and require special consideration.

Many prompt diagnostic methods are available including screening tests like wet mount microscopy, Gram stain, catalase test, Nitrate test, Triphenyl tetrazolium chloride test, but gold standard method for diagnosis of UTI is quantitative urine culture. Urine culture is an expensive, time consuming procedure and needs a well-equipped microbiology laboratory with experienced technicians. While On the other side, Screening tests of urine sample are designed to allow early detection of infection in the emergency department and an earlier initiation of the treatment. They are inexpensive, less timeconsuming, easy to perform, no expertise required to perform and are useful in small laboratories having no culture facility.

Due to clinical significance of early diagnosis of UTI, different screening tests are used widely, but their performance characteristics are still questionable. The aims of the present study were: to study the prevalence of bacterial pathogens causing urinary tract infection among children; to evaluate the accuracy of different screening test for diagnosis of UTI, keeping semi quantitative culture as the gold standard (Mundhada et al., 2016).

\section{Materials and Methods}

The present study was carried out in the Department of Microbiology, shri shankaracharya institute of medical sciences, Chhattisgarh during Jan 2018 to Nov 2018. Children ranging from 2 months up to fifteen years of age of either sex seen in the OPD or Wards with a clinical diagnosis of UTI were taken as the study subjects.

\section{Processing of specimen}

The midstream, clean catch specimens of urine were collected in sterile universal container from paediatric patients with clinical diagnosis of UTI.

In children under 2 years of age urine was collected in a sterile bag and in above 2 years freshly passed clean- catch mid- stream urine was collected aseptically (Pal N et al., 2016).

Urine specimens were screened for significant bacteriuria by following screening tests (Collee et al., 2006; Palmer, 1997; Hinton and Hoeve, 1965; Srihari et al., 2012):

Wet Film Examination

Triphenyl Tetrazolium chloride reduction test (TTC test)

Gram Staining. The following screening tests were done.

Catalase test

Modified Griess Nitrite Test

Wet film examination: Pus cells/high power field (hpf) were counted. About 20 fields were searched. Finding $>1$ pus cell/ 7 hpf indicates significant pyuria. Apart from pus cells, RBC, any casts, bacteria, yeast cells were also noted. Gram Staining: The presence of $\geq 1$ bacteria/Oil immersion field in 20 fields 
correlated with the diagnosis of significant bacteriuria of $\geq 105 \mathrm{CFU} / \mathrm{ml}$ of urine.

Catalase test: Four drops of $10 \%$ hydrogen peroxide were added in $2 \mathrm{ml}$ of urine in the test tube. The mixture was shaken gently for 5 seconds. Formation of effervescence to form a complete ring or layer on the surface of the liquid within 1 to 2 minutes was taken as positive test. Positive control-Staphylococcus aureus and Negative control - Enterococci species.

Triphenyl tetrazolium chloride (TTC) test: $2 \mathrm{ml}$ of urine was taken in a sterile test tube and $0.5 \mathrm{ml}$ of working triphenyl tetrazolium chloride reagent was added. This mixture was incubated at 370C for 4 hours. Formation of red precipitate indicated a positive test.

Modified Griess nitrite test: $8 \mathrm{ml}$. of urine was taken in a test tube and centrifuged this for 15 minutes. The supernatant was decanted. To the precipitate, $0.5 \mathrm{ml}$. of a $10 \%$ solution of potassium nitrate was added. This was incubated for one and half hour at room temperature.

Then, $1 \mathrm{ml}$ of the Griess reagent $(0.5 \mathrm{ml}$ of solution A: Sulphanilic acid $+0.5 \mathrm{ml}$ of solution B: $\alpha$-naphthylamine) was added to it. The development of a pink or a red colour in a matter of seconds was considered to be a positive test. Asepsis was strictly observed. Positive control $-E$. coli and Negative control - Enterococci species.

\section{Culture}

Urine specimens from 247 clinically diagnosed UTI patients were subjected to culture for identification of different microorganisms.

\section{Quantitative culture}

Calibrated bacteriological loop (calibrated to
$1 \mu 1)$ was used to inoculate urine sample to the culture media (Blood agar and MacConkey agar).

\section{Identification of bacteria}

All bacteria are identified by routine standard technique (Collee et al., 2006).

\section{Statistical analysis}

Sensitivity, specificity, positive and negative predictive value were calculated according to the following formulae

Sensitivity $=$ True positive/(True positive + False negative), the probability that the screening test will be positive in patients with urinary infection (positive culture).

Specificity $=$ True negative $/($ True negative + false positive) the probability that the screening test will be negative in patients without urinary infection (negative culture).

Positive predictive value $=$ True positive/(True positive + false positive), the probability that urinary infection is present when the screening test is positive.

Negative predictive value $=$ True negative/(True negative + False negative), the probability that a urinary tract infection is not present when the screening test is negative.

True positive stands for (Screening test and culture both positive), False positive stands for (Positive screening test and negative culture), True negative stands for (Screening test and culture both negative) and False negative stands for (Screening test negative and culture positive).

\section{Antimicrobial susceptibility test}

Antimicrobial susceptibility test was performed by using Kirby Bauer disc diffusion 
method by following the Clinical Laboratory Standards Institute (CLSI) guidelines.

\section{Results and Discussion}

Out of 247 samples taken from paediatric group $58 \quad(23.48 \%)$ showed significant bacteriuria by the semiquantitative culture method which is similar to that reported by (Pal et al., 2016). in our study there is female predominance (67.24\%) except during first year of life. where male is most affected which is correlated with the finding of Gorelick et al., (1999). The reason of this disease being more common in female child is probably short urethra in females besides others factors (Shrestha et al., 2013). Most common organisms isolated was $-E$. coli (65.51\%) followed by Proteus species (13.79\%), Klebsiella species (10.34\%), Pseudomonas aeruginosa (3.44 \%) and Staphylococcus aureus (4.34\%), one isolate each of Enterococci species (1.72\%) and Staph saprophyticus species (Table 1 and 2).

Table.1 Age and sex distribution of culture positive urinary isolates among paediatric population

\begin{tabular}{|l|l|l|l|l|l|}
\hline & $\mathbf{2 m - 1 y r}$ & $\mathbf{1 - 5 y r}$ & $\mathbf{5 - 1 0 y r}$ & $\mathbf{1 0 - 1 5 y r}$ & Total(58) \\
\hline Male & $4(21.05 \%)$ & $8(42.10 \%)$ & $4(21.05 \%)$ & $3(15.78 \%)$ & $19(\mathbf{3 2 . 7 5 \%})$ \\
\hline Female & $5(12.82 \%)$ & $18(46.15 \%)$ & $9(23.07 \%)$ & $8(20.51 \%)$ & $39(67.24 \%)$ \\
\hline
\end{tabular}

Table.2 Frequency of organisms isolated from urine sample on culture $(\mathrm{N}=58)$

\begin{tabular}{|l|l|}
\hline Organism isolated & Number (\%) \\
\hline E.coli & $38(65.51)$ \\
\hline Klebsiella species & $6(10.34)$ \\
\hline Proteus species & $8(13.79)$ \\
\hline Pseudomonas aeruginosa & $2(3.44)$ \\
\hline Staphylococcus aureus & $2(3.44)$ \\
\hline Staphylococcus saprophyticus & $1(1.72)$ \\
\hline Enterococci species & $1(1.72)$ \\
\hline
\end{tabular}

Table.3 Sensitivity, specificity and predictive value of various screening tests

\begin{tabular}{|l|l|l|l|l|}
\hline Tests & Sensitivity $(\%)$ & Specificity $\mathbf{( \% )}$ & $\begin{array}{l}\text { Positive } \\
\text { predictive } \\
\text { value (\%) }\end{array}$ & $\begin{array}{l}\text { Negative } \\
\text { predictive } \\
\text { value (\%) }\end{array}$ \\
\hline Wet mount & 63.04 & 86.42 & 69.60 & 70.85 \\
\hline Gram stain & 78.26 & 88.89 & 85.71 & 82.76 \\
\hline Catalase test & 94.93 & 90.74 & 89.73 & 95.45 \\
\hline TTC test & 86.23 & 95.67 & 94.44 & 89.08 \\
\hline $\begin{array}{l}\text { Modified } \\
\text { Griess Nitrite } \\
\text { test }\end{array}$ & 86.95 & 94.44 & 93.02 & 89.47 \\
\hline
\end{tabular}

For all the organisms isolated (Gram positive and Gram negative), imipenem was the most sensitive drug 55 (94.82\%), followed by nitrofurantoin $52 \quad(89.65 \%)$, amikacin 
48(82.75\%), gentamicin $45(77.58 \%)$ and ciprofloxacin $42(72.41 \%)$. Evaluation of various screening tests in relation to the culture is as given below (Table 3). The diagnosis of UTI is currently based on concept of quantitative bacteriuria, but for mass detection of UTI especially in risk groups like diabetics, antenatal cases and children in health surveys, reliable screening method is essential. The purpose of urine screening is to eliminate those specimens that do not contain significant number of bacteria. In present study, sensitivity and specificity of wet mount (pyuria) was $63.33 \%$ and $57.14 \%$ respectively. Similar results were noted by soma et al., (2018). There were 12 samples in which pus cell were found in urine but there was no significant growth on culture media indicating either sterile pyuria or disintegration of the pus cells due to the presence of Proteus, Klebsiella and Pseudomonas in alkaline urine. Also the positive predictive value was less i.e. $61.29 \%$ making this test less useful in the diagnosis of urinary tract infection. The urine Gram stain, has been proposed both as a more sensitive and specific method for identifying patients with UTI, especially as a screening test when compared with culture (Mustafa et al., 2008). But in our study, sensitivity was $84.61 \%$ which is similar to the finding of (Mustafa et $a l ., 2008)$ and specificity of Gram stain 85.71 $\%$ which was comparable to results noted by (Anchinmane et al., 2018).

In this study, Catalase test was found to be 93.75\% sensitive and $69.23 \%$ specific whereas $88.63 \%$ and $75.86 \%$ sensitivity and specificity respectively were noted by Ninama (2016). There were 8 samples which were catalase positive but did not show any growth on culture media which might be due to haematuria in the patients. By Triphenyl Tetrazolium chloride(TTC) test we obtained 88.88 sensitivity but lower specificity 63.66\%.Other worker like Agrawal et al.,
(1986) and Wagle et al.,(1989) noted similar finding.

Specificity (95.65\%) of Modified Griess nitrate test was more than Sensitivity $(91.66 \%)$ in present study.so test is more useful in rolling out UTI in patients also the positive predictive value is $97.05 \%$ Similar finding were noted by Mustafa et al., (2008). while in contrast result was noted by Taneja et al., (2010) Total 3 false negative samples were noted as nitrate test does not detect organisms unable to reduce nitrate to nitrite, such as Enterococci, Staphylococci species, Acinetobacter etc.

Rapid diagnostic tests can rule out negative samples, are economical, save valuable time and thus useful in high-end laboratories. Screening is also required in special circumstances where it is difficult to identify UTI on basis of clinical criteria alone but where early diagnosis and prevention of complications affords significant benefit (e.g. children, and post renal transplant patients) (Deville et al., 2004). But due to different sample population in different studies like high risk population, Gender, Children or because of variation in procedure while performing tests, it results in variation in performance of different screening tests. Therefore a combination of screening tests should be used for diagnosis of UTI as there is no single test with $100 \%$ sensitivity and specificity.

In conclusion, urine culture remains gold standard method for diagnosis and confirmation of UTI in the laboratories were adequate culture facilities are available. Timely diagnosis and prompt treatment of a febrile UTI is important to eradicate the acute infection, to prevent bacteremia (in particular, young infants less than 3 months of age), to improve the clinical condition, and possibly to reduce the likelihood of renal damage. But in 
resource limited area where culture facilities are not available or labs with high patient load combination of screening test will be helpful to reduce morbidity associated with urinary tract infection.

\section{References}

Anchinmane VT, Preet K, Sankhe S. Utility of urinary gram stain as a diagnostic method for urinary tract infection. Int $\mathrm{J}$ Res Med Sci 2018;6:610-2.

Agrawal SK, Das R, Goel M, Kumar M. Tetrazolium reduction test in diagnosis of urinary tract infections. Indian I PatholMicrobiol 1986; 29: 61-65.

Christopher D, Doern, A. Susan, E. Richardsonb. Diagnosis of Urinary Tract Infections in Children. Sep 2016 Vol 54 No. 9 Journal of Clinical Microbiology.

Collee JG, Miles RS, Watt B. Laboratory strategy in the diagnosis of infective syndrome. In: Colle JG, Fraser AG, Marimon BP, Simmons A, editors. Mackie and McCartney Practical Medical Microbiology. 14th ed. Edinburg: Elsevier Churchill Livingstone; 2006. p.84-90.

Deville WLJM, Yzermans JC, van Duijin NP, Bezemer D, van der Windt DAWM, Bouter LM. The urine dip stick test useful to rule out infections. A metaanalysis of the accuracy. BMC Urology 2004; 4: 4-17.

Elder JS, Urinary tract infections. Kliegman RM, Behrman RE, Jenson HB, Stanton BE, editors. Nelson Text book of Pediatrics. Philadelphia: 2007. Pp. 2223-8.

Gorelick MH, Shaw KN. Screening Test for Urinary Tract Infection in Children: A meta analysis. Pediatrics 1999; 104:54.

Hinton NA, Hoeve E. The Detection of Significant Bacteriuria: An Assessment of the Triphenyl tetrazolium Chloride
Reduction Test. Canad. Med. Ass. J. 1965; Vol. 93: 639-42.

Mustafa Yildirim, İdris SAHİN, Abdülkadir Küçükbayrak, Şükrü Öksüz,Selda Acar, M. Tevfik Yavuz Düzce Tıp Fakültesi Dergisi the validity of the rapidly diagnostic tests for early detection of urinary tract infection. 2008; 3:39-42.

Mundhada SG, Ingole KV, Bhise MP, and Shaikh SV. Evaluation of different screening tests for detection of Urinary Tract Infections in pregnant women attending the antenatal clinic Int.J.Curr.Microbiol.App.Sci (2016) 5(4): 772-777.

Ninama AB, Shah PD. Comparison of various screening methods for presumptive diagnosis of significant bacteriuria. Int $\mathbf{J}$ Med Sci Public Health 2016; 5: 10661069.

Pal N, Rit K, Naskar S, Kumar S, Guhathakurata R. A study of bacteriological and antibiotic susceptibility profile of pediatric urinary tract infection with special emphasis on extended spectrum beta- lactamase production in a tertiary care hospital of Eastern India Int J Health Allied Sci 2016; 5: 257-62.

Palmer LS, Richards I, Kaplan W. Clinical evaluation of a rapid diagnostic screen (Uriscreen) for bacteriuria in children. $\mathrm{J}$ Urol 1997; 157: 654-657.

Shrestha SP, Shrestha AK, Lamsal L and Joshi M. Bacteriological profile of urinary tract infection in children at GMC teaching hospital. Journal of Chitwan Medical College, 2013; 3(5): 22-25.

Soma Mondal, Avijit Mondal, Kuhu Pal, Indira Paul Utility of simple urinary screening tests to rule out UTI in Pediatric population IOSR-JDMS 2018; vol 17(2): 24-28.

Srihari A, Beeregowda YC, Vishnu Vardhan Reddy T. A comparative study of Griess 
nitrate test and urinary culture in detection of asymtomatic bacteriuria in children. Int J Biol Med Res. 2012; 3(1): 1439-41.

Performance Standards for Antimicrobial Susceptibility Testing; Twenty-fifth Informational Supplement. CLSI document M100-S25. Wayne, PA: Clinical and Laboratory Standards Institute; 2015.

Taneja N, SS Chatterjee, M Singh, S Sivapriya, M Sharma, SK Sharma.
Validity of Quantitative Unspun Urine Microscopy, Dipstick Test Leucocyte Esterase and Nitrite Tests in Rapidly Diagnosing Urinary Tract Infections. JAPI Aug 2010. VOL. 58:485-8 Wagle N, Vaidya A, Joshi S, Merchant S. Triphenyl Tetrazolium Chloride (TTC) dye test for quick diagnosis of urinary tract infection. Indian Journal of Pediatrics, 1989 sept; Vol. 56(5): 63538.

\section{How to cite this article:}

Smita Bawankar, Aakanksha Sharma, Khyati Jain, Surendra Chauhan and Mustafa. 2019. Utility of Screening Test in Early Diagnosis of Urinary Tract Infection in Children. Int.J.Curr.Microbiol.App.Sci. 8(01): 1700-1706. doi: https://doi.org/10.20546/ijcmas.2019.801.180 